\title{
Zoning of Nitrite and Nitrate Concentration in Groundwater Using Geografic Information System (GIS), Case Study: Drinking Water Wells in Yazd City
}

\author{
Reza Ali Fallahzadeh ${ }^{1}$, Seyed Ali Almodaresi2*, Mohamad Mehdi Dashti' ${ }^{1}$, Ahmad Fattahi ${ }^{3}$, \\ Mojtaba Sadeghnia ${ }^{3}$, Hadi Eslami1', Rasoul Khosravi1, Roya Peirovi Minaee ${ }^{1}$, \\ Mahmoud Taghavi ${ }^{4}$ \\ ${ }^{1}$ Department of Environmental Health Engineering, Faculty of Public Health, Shahid Sadoughi University of \\ Medical Sciences, Yazd, Iran \\ ${ }^{2}$ Department of GIS \& RS, Engineering College, Yazd Branch, Islamic Azad University, Yazd, Iran \\ ${ }^{3}$ Department of Occupational Health Engineering, School of Public Health, Shahid Sadoughi University of \\ Medical Sciences, Yazd, Iran \\ ${ }^{4}$ Department of Environmental Health Engineering, Zabol University of Medical Sciences, Zabol, Iran \\ Email: "almodaresi@iauyazd.ac.ir
}

Received 1 February 2016; accepted 25 March 2016; published 28 March 2016

Copyright (C) 2016 by authors and Scientific Research Publishing Inc.

This work is licensed under the Creative Commons Attribution International License (CC BY).

http://creativecommons.org/licenses/by/4.0/

c) (i) Open Access

\section{Abstract}

Studies have demonstrated that the presence of nitrate and nitrite in drinking water can cause some disease such as cancer and blu baby in the infant. The Environmental Protection Agency (EPA) has since adopted the $10 \mathrm{mg} / \mathrm{L}$ standard as the maximum contaminant level (MCL) for nitrate-nitrogen and $1 \mathrm{mg} / \mathrm{L}$ for nitrite-nitrogen for regulated public water systems. Given the importance of nitrate and nitrite in drinking water as well as GIS ability in spatial analysis of various factors in the groundwater, this study aimed to evaluate concentration of nitrate and nitrite in the drinking water wells of Yazd using two IDW (Inverse Distance Weighting) and Kriging models. In this descriptive study, the applied data on the water quality of underground water of Yazd Environmental Health Office and the average annual nitrate and nitrite in 2015 were related to 24 wells in the studied area. The nitrate and nitrite rate in groundwater in wells was compared to the standard amount of Institute of Standard and Industrial Researches and then was analyzed via Arc GIS software using IDW and Kriging interpolation methods. The mean concentration of nitrate was $17.62 \pm 3.08 \mathrm{mg} / \mathrm{l}$ and for nitrite was $0.011 \pm 0.003 \mathrm{mg} / \mathrm{l}$ in the wells. In the all studied zone, the nitrate and nitrite rate was in the standard range according to the National Standard of Iran (No.

"Corresponding author.

How to cite this paper: Fallahzadeh, R.A., et al. (2016) Zoning of Nitrite and Nitrate Concentration in Groundwater Using Geografic Information System (GIS), Case Study: Drinking Water Wells in Yazd City. Journal of Geoscience and Environment Protection, 4, 91-96. http://dx.doi.org/10.4236/gep.2016.43008 
1053). In this study, Kriging interpolation method was more efficient than IDW method.

Keywords

Drinking Water, Nitrite and Nitrate Concentration, Geographic Information Systems, Interpolation

\section{Introduction}

Nitrogen is an element on the nature. Nitrate and nitrite are two forms of it that can be found in the nature. Drinking water may be polluted by this chemicals, consumption of water that contaminated by this chemicals can cause some serious disease such as cancer, methaemoglobinaemia, etc. Nitrite is more dangerous as nitrate and nitrate can reduce to nitrite, so these reductions can increase the hazardous of this material. Because of alkalin stomach, the infant can be affacted more by nitrate, in the alkalin stomach, nitrate rapidly changed to nitrite, and nitrite can case methaemoglobinaemia, so the HB is unable to transport oxygen to the tissues [1].

Many reasons can cause increase in nitrates, nitrites and other nutrients in ground water such as influence agricultural drainage, influence of industrial wastewater and the type of soil [2] [3].

Today, efforts have been made to use of the new computer and electronic systems for water monitoring [4]. A good way to prevent groundwater from pollutions is to investigate the quality of ground water and spatial variability for monitoring water resources. Geographic information system (GIS) is considered as a new and powerful technology that can be used to identify data, analyze, interpret, and consequence the data [5]. Inverse distance weighting (IDW) is one of the spatial analysis methods, the effective factor in this model is the distance fort weighting. Another method used in spatial analysis is Kriging model. In this interpolation method which is based on regression, the weight is not only allocated to the distance between the surrounding points, but also is based on the correlation between the measured points [6] [7]. Numerous studies use GIS as explored spatial analyses, interpolation, and zoning methods all over the world [8]-[12]. In recent years, many researches have been carried out in Iran to study the spatial change of quality and quantity properties of groundwater [13]-[18]. While both Kriging and IDW have shown themselves to be suitable in terms of spatial interpolation [15] [17]-[19] in most studies that compared kriging and IDW, Kriging is found to be more accurate [14] [17] [18] and only in a few does IDW show more precision [16]. This research aims to range the contamination of groundwater resources with nitrite and nitrate using Kriging and IDW methods in the wells of Yazd city.

\section{Materials and Methods}

The research area involved Yazd city including north to the south of the Yazd City at longitude 54.15 to 54.35 and latitude 31.58 to 31.44. Due to its geographical location in the central plateau of Iran, Yazd province has a hot and dry desert climate [19] (Figure 1).

In this descriptive study, the data related to the quality of underground water of Yazd Environmental Health Office as well as the average annual nitrate and nitrite in 2015 (three sampling period per year) were used, which were related to 24 wells in the studied area. In this study used of Arc GIS software in order to spatially analyze the data concerning the Nitrate and Nitrite concentration in ground water in the city of Yazd.

In this study the Krigging and IDW methods used for investigate concentration changes of nitrate and nitrite in groundwater in Yazd in term of space.

\section{Results}

In the present study, the nitrate and nitrite concentration of the groundwater was investigated in the Yazd city wells. So, the sampling results of 24 wells in the Yazd city were analyzed. Statistical description (mean, minimum, maximum and standard deviation) related to nitrate and nitrite concentrations in the water of wells are displayed in Table 1.

According to Iran's standard of drinking water (No. 1053), Nitrate concentration should be least than $50 \mathrm{mg} / \mathrm{l}$ and nitrate concentration should be least than $3 \mathrm{mg} / \mathrm{l}$. The nitrite and nitrate rate was less than the maximum allowable amount according to Iran’s standard (No. 1053). 


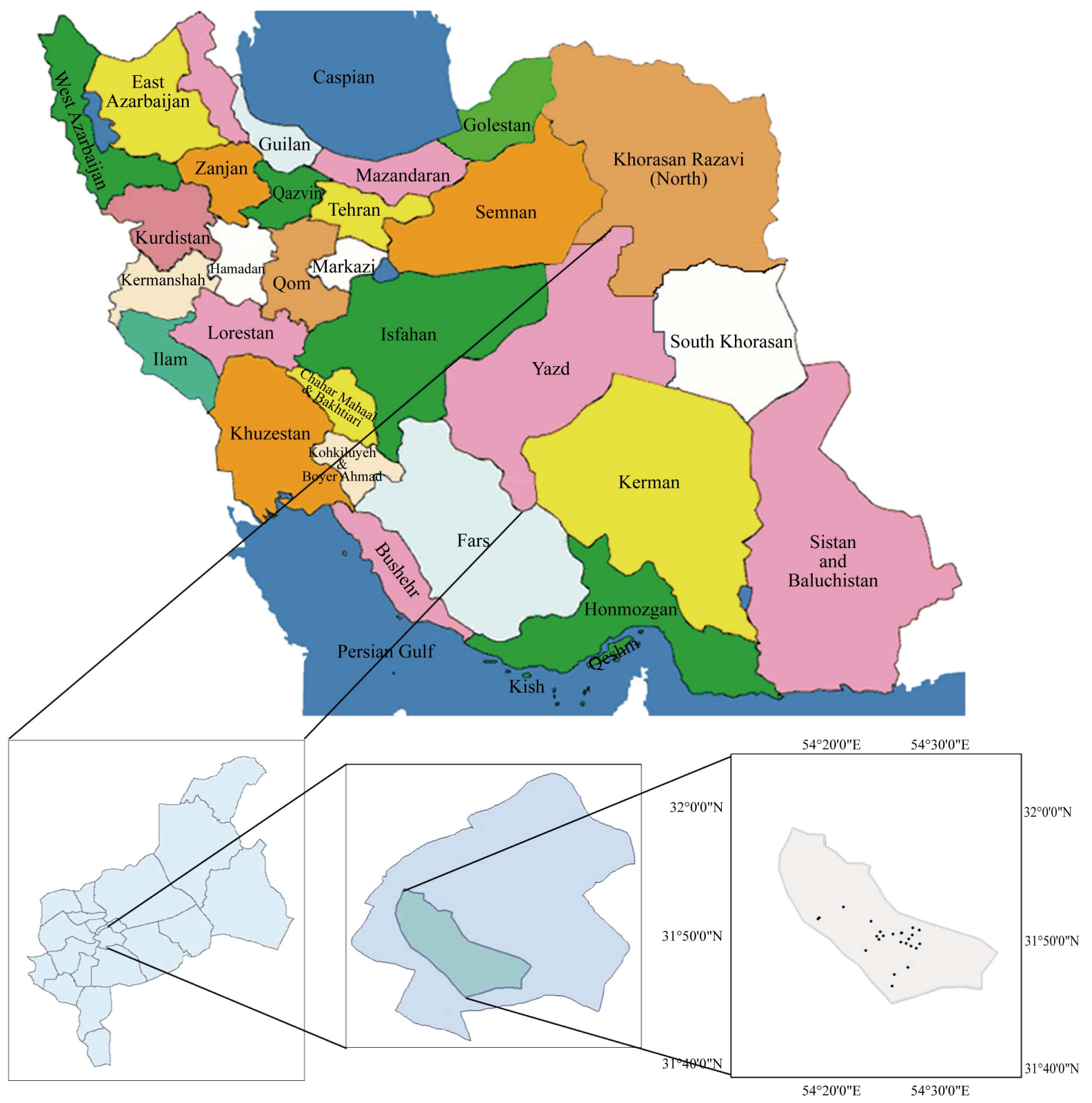

Figure 1. The location of Yazd city in the country and Yazd province.

Figure 2(a) and Figure 2(b) respectively indicate zoning via Kriging method and IDW for the nitrate rate and Figure 3(a) and Figure 3(b) show zoning for the nitrite rates in the Yazd city wells.

\section{Discussion}

In this study, the concentration of nitrate and nitrite in the wells of Yazd city was studied. Given the average concentration in 2015, it was found that concentration of nitrate and nitrite in various wells was less than the maximum allowable amount according to Iran's standard. According to the maps of nitrite and nitrate concentration in the studied area, it can be concluded that in studied wells no problem of nitrate and nitrite concentration over the permitted limit (Least than $50 \mathrm{mg} / \mathrm{l}$ for nitrate and $3 \mathrm{mg} / \mathrm{l}$ for nitrite) was observed and therefore there is no concern regarding related diseases.

The rate of nitrate in groundwater may be influenced by some characterizes such as sewage and the physical characteristics of regional soil such as bedrock type, soil type, well depth, well structure and its domain. Lack of 
Table 1. The statistical description of nitrate and nitrite in the wells of Yazd city.

\begin{tabular}{|c|c|c|}
\hline Wells Number & $\mathrm{NO}_{3}$ Concentration $(\mathrm{mg} / \mathrm{l})$ & $\mathrm{NO}_{2}$ Concentration (mg/l) \\
\hline 1 & 12 & 0 \\
\hline 2 & 11 & 0.01 \\
\hline 3 & 16 & 0.02 \\
\hline 4 & 12.8 & 0 \\
\hline 5 & 14 & 0.02 \\
\hline 6 & 12 & 0.01 \\
\hline 7 & 15.2 & 0.01 \\
\hline 8 & 12.6 & 0.01 \\
\hline 9 & 13.2 & 0.01 \\
\hline 10 & 16 & 0.02 \\
\hline 11 & 14 & 0.01 \\
\hline 12 & 11.6 & 0 \\
\hline 13 & 9.05 & 0 \\
\hline 14 & 11 & 0 \\
\hline 15 & 10 & 0 \\
\hline 16 & 12 & 0.02 \\
\hline 17 & 26.2 & 0.03 \\
\hline 18 & 29.9 & 0.02 \\
\hline 19 & 16 & 0.02 \\
\hline 20 & 22 & 0.01 \\
\hline 21 & 18 & 0.01 \\
\hline 22 & 12.8 & 0 \\
\hline 23 & 12.4 & 0.01 \\
\hline 24 & 12.6 & 0.01 \\
\hline Minimum Concentration (mg/l) & 9.05 & 0 \\
\hline Maximum Concentration (mg/l) & 29.9 & 0.03 \\
\hline Mean Concentration (mg/l) & 17.62 & 0.011 \\
\hline Standard Deviation & \pm 3.08 & \pm 0.003 \\
\hline
\end{tabular}
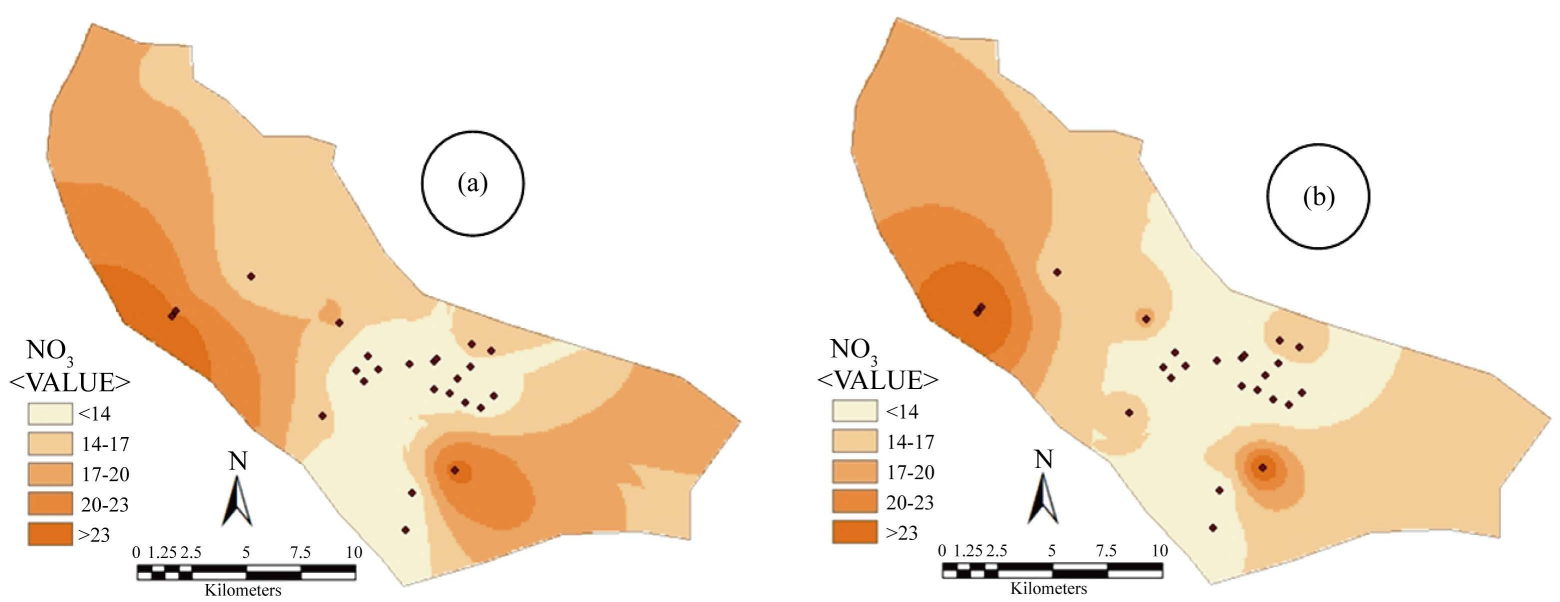

Figure 2. Zoning nitrate concentration in wells using (a) Kriging and (b) IDW methods. 

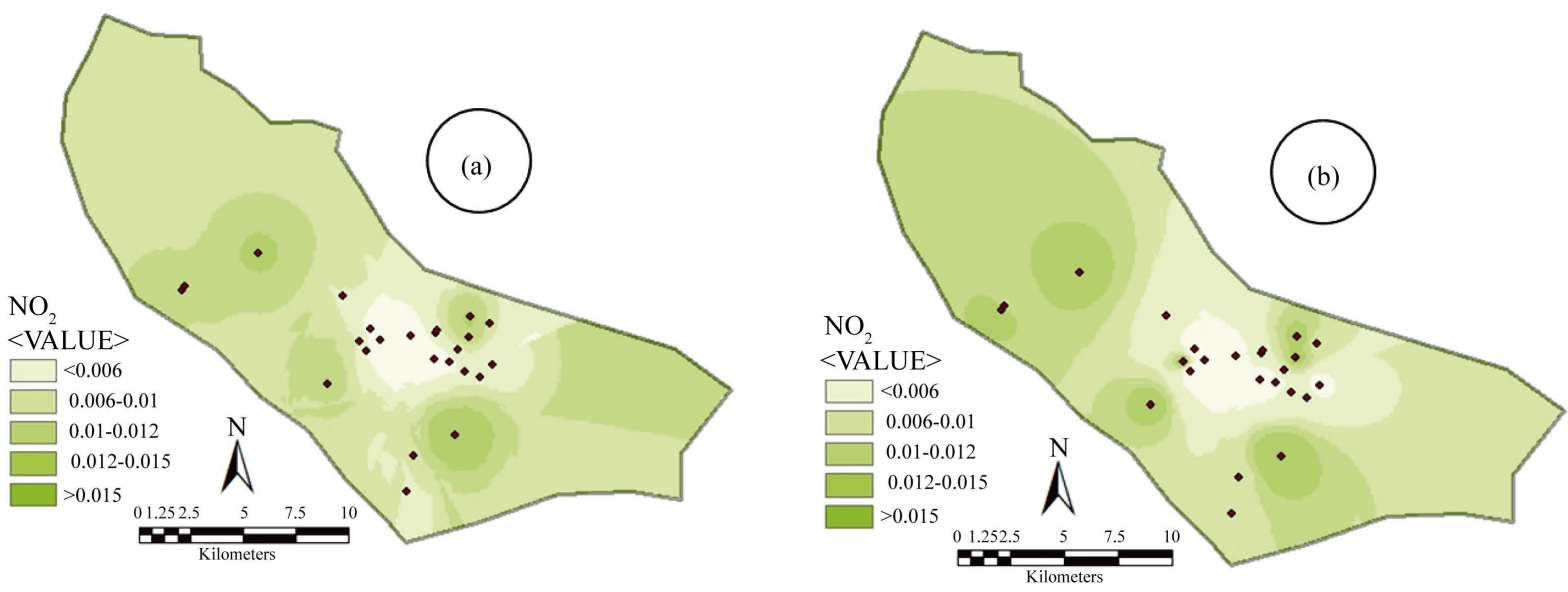

Figure 3. Zoning nitrite concentration in wells using (a) Kriging and (b) IDW methods.

water quality control, flow gradient from up sites to wells and inappropriate location of wells in the plain can also be affective factors of increasing nitrate concentration in wells [20]. The higher nitrate concentrations found in the south and the west of the study areas might be due to the presence of the extensive farming in that zone.

Badeenezhad et al. (2012) conducted a study and evaluated nitrate concentrations in groundwater from Shiraz (Iran) by using of ArcView GIS. In this study 220 samples from 55 wells taken in the dry and wet seasons. They demonstrated that by increased the depth of well, nitrate concentrations decreased [13]. In the Ostovari et al study (2012), investigated the spatial variability of nitrate in 32 wells of the Lordegan aquifer during 2010. Their results demonstrated that in the all samples the nitrate concentrations were below the WHO limit. In this study the IDW was used for zoning the aquifer. According to the results of IDW mapping, the northern part of the aquifer has the highest nitrate concentrations; it can be related to the leaching of nitrate from agricultural soils [16]. Mousavifazl et al. (2013) conducted a study for evaluated nitrate and sodium, in the groundwater of 276 wells in Mashhad (Iran). They used of both Kriging and IDW methods for this study, both of metod had good accuracy in estimating the amount of nitrates. Their results also indicated that Kriging could be more appropriate based on its root mean square error in comparison to inverse distance weight and normal distance weight [17]. Abdolahiman-sorkhani et al. (2012) conducted a study for evaluate the spatial distribution of nitrate in 56 wells in Shahrekord (Iran), to this propose they used of Kriging, co-Kriging, inverse distance weighting, and radial basis functions. According to their results, Kriging was the most accurate method for modeling nitrate spatial distribution because of its minimum RMSE. So they used of ordinary Kriging for showing the nitrate spatial distribution in groundwater [14]. In a study that conducted by Taghizadeh et al., (2009) evaluated the spatial variation of water quality characteristics using Kriging, co-Kriging and IDW interpolation methods in Rafsanjan, Iran. According to the results of this study, Kriging and co-Kriging methods were more suitable than the IDW method [18]. In a study Fathi Hafshejani et al. (2013) evaluated the spatial variability and mapping of nitrate and phosphate in 100 agricultural wells of Shahrekord (Iran) groundwater from 2006 to 2011. The concentrations of nitrate and phosphate were high in the south part of the aquifer; it might be caused by the presence of the municipality treatment plant, intensive cattle farming, shallower water-table, and the inward flow gradient in this area [15].

Mixing water that has a low nitrogen concentration with regional water resources and installing a suitable purification system for drinking water can help in reducing the nitrate concentration [3].

\section{Conclusion}

According to the results of the current study, Kriging seems to be more appropriate than IDW for estimating the nitrate content in the groundwater of the Yazd city wells. In the all studied zone, the nitrate and nitrite rate is in the standard range according to the National Standard of Iran (No. 1053). In this study, Kriging interpolation method is more efficient than IDW method.

\section{References}

[1] World Health Organization, Geneva (1998) Guidelines for Drinking-Water Quality. 2nd Edition, Addendum to Vol. 2, 
Health Criteria and Other Supporting Information.

[2] Azadi, N.A., Fallahzadeh, R.A. and Sadeghi, S. (2015) Dairy Wastewater Treatment Plant in Removal of Organic Pollution: A Case Study in Sanandaj, Iran. Environmental Health Engineering and Management Journal, 2, 73-77.

[3] Kheradpisheh, Z., Almodaresi, S.A., Khaksar, Y. and Rafati, L. (2014) Zoning of Groundwater Contaminated by Nitrate Using Geostatistics Method (Case Study: Bahabad Plain, Yazd, Iran). Desert, 19, 83-90.

[4] Fallahzadeh, R.A., Gholami, M., Madreseh, E., Ghaneian, M.T., Farahzadi, M.H., Askarnejad, A.A. and Sadeghi, S. (2015) Comparison of Using an Electronic System and Conventional Monitoring Method for Monitoring the Quality of Drinking Water and Defects Discovery in Rural Area Water Distribution Network of Abarkouh, Iran. Health, 7, 35. http://dx.doi.org/10.4236/health.2015.71005

[5] Ehsani, H., Hasani, A., Shariat, M., et al. (2007) Evaluation of Nitrate Variation and Total Dissolved Solids Trend in Drinking Water Using GIS Hamedan Plain Ground. 10th National Conference on Environmental Health. Hamadan, 9-10 November 2007, 67-76.

[6] Cressie, N.A.C. (1993) Statistics for Spatial Data. John Wiley \& Sons, Inc., Hoboken. http://dx.doi.org/10.1002/9781119115151.ch1

[7] Schabenberger, O. and Gotway, C.A. (2005) Statistical Methods for Spatial Data Analysis. CRC Press, United States.

[8] Gaus, I., Kinniburgh, D.G. and Webster, R. (2003) Geostatistical Analysis of Arsenic Concentration in Groundwater in Bangladesh Using Disjunctive Kriging. Environmental Geology, 44, 939-948. http://dx.doi.org/10.1007/s00254-003-0837-7

[9] Barca, E. and Passarella, G. (2008) Spatial Evaluation of the Risk of Groundwater Quality Degradation. A Comparison between Disjunctive Kriging and Geostatistical Simulation. Environmental Monitoring and Assessment, 137, 261-273. http://dx.doi.org/10.1007/s10661-007-9758-3

[10] Dayani, M., Mohammadi, J. and NaderiKhorasgani, M. (2010) Geostatistical Assessment of Pb and the Related Soil Physical and Chemical Properties in Near-Surface Soil around Sepahanshahr, Isfahan. DESERT, 15, 139-149.

[11] Motaghian, H.R. and Mohammadi, J. (2012) Statistical and Geostatistical Appraisal of Spatial Variability of Aggregate Stability and Aggregate-Associated Organic Carbon Content on a Catchment Scale in a Semi-Arid Region, Central Iran. DESERT, 17, 27-39

[12] Jafari, M., Mohammad Asgari, H., Tahmoures, M. and Biniaz, M. (2011) Assessment of Soil Property Spatial Variation Based on the Geostatistical Simulation. DESERT, 16, 87-101.

[13] Badeenezhad, A., Gholami, M., JonidiJafari, A. and Ameri, A. (2012) Factors Affecting Nitrate Concentrations in Shiraz Groundwater Using Geographical Information System (GIS). Tolooe Behdasht, 11, 47-56.

[14] Abdolahi Mansorkhani, M., Mohammadzadeh, H. and Amini, M. (2012) Evaluation of Nitrate Spatial Variations in Shahrekord Aquifer Using Geostatistical Methods. National Conference on Water Flow and Pollution, Tehran, 23-24 May 2012, 1-9.

[15] Fathi Hafshejani, E. and Beigi Harchegani, H. (2013) Spatial Variability and Mapping of Nitrate and Phosphate in Shahrekord Groundwater over a Period of Five Years. Journal of Science and Technology of Agriculture and Natural Resources, Water and Soil Science, 17, 63-75.

[16] Ostovari, Y., Beigi Harchegani, H. and Davoodian, A.R. (2012) Spatial Variation of Nitrate in the Lordegan Aquifer. Water and Irrigation Management, 2, 55-67.

[17] Mousavifazl, H., Alizadh, A. and Ghahraman, B. (2013) Application of Geostatistical Methods for Determining Nitrate Concentrations in Groundwater (Case Study of Mashhad Plain, Iran). International Journal of Agriculture and Crop Sciences, 5, 318-328.

[18] Taghizadeh-Mehrjardi, R., Zareian-Jahromi, M., Mahmoodi, S., Heidari, A. and Sarmadian, F. (2009) Investigation of Interpolation Methods to Determine Spatial Distribution of Groundwater Quality in Rafsanjan. Iranian Journal of Watershed Management Science, 2, 63-70.

[19] Charkhkarzadeh, R., Derakhshan, Z., Miri, M., Ehramposh, M.H., Lotfi, M.H. and Jafari Nodoshan, V. (2015) Examining Changes Trend of Fluoride Concentration in Groundwater Using Geo-Statistical Technique and Its Zoning in Geographic Information System (GIS), Case Study: Drinking Water Wells in Yazd-Ardakan Plain. JCHR, 4, 220-233

[20] FiratErsoy, A., Ersoy, H. and Gültekin, F. (2007) Nitrate, Nitrite and Ammonia Contamination in Ground Water: A Case Study from Gümüphacýköy Plain, Turkey. Asian Journal of Water, Environment and Pollution, 4, 107-118. 